\title{
Práticas de solidariedade e a humanização da
}

sociedade

\section{Practices of solidarity and the humanization of society}

LUIZ AlEXANDRE RossI ${ }^{a}$

\section{Resumo}

A construção de uma sociedade sadia acontece preferencialmente a partir de medidas de proteção daqueles que vivem na periferia e estão, em razão disso, sem possibilidade de proteção externa ou de autoproteção exatamente porque se constituem seja como pessoas ou grupos fracos e/ou enfraquecidos e empobrecidos. No artigo se objetiva abordar apenas duas situações de proteção dos mais vulneráveis - Dt 24,14-15 e 17-18 - e a maneira pela qual eles são protegidos pelo legislador deuteronômico.

Palavras-chave: Solidariedade. Pobre. Proteção social. Humanização.

\section{Abstract}

The construction of a healthy society happens preferentially from measures of protection of those who live in the periphery and are, therefore, without the possibility of external protection or self-protection precisely because they constitute themselves as weak and/or weakened and impoverished people or groups. The article aims to address only two situations of protection of the most vulnerable - Dt 24,14-15 e 17-18 and how they are protected by the deuteronomic legislator.

Keywords: Solidarity. Poor. Social protection. Humanization.

\footnotetext{
a Pontifícia Universidade Católica do Paraná (PUCPR), Curitiba, PR, Brasil. Doutor em Ciências da Religião, e-mail: luizalexandrerossi@yahoo.com.br
} 


\section{Introdução}

Em Deuteronômio 24,5-22 encontramos uma série de medidas de proteção aos mais vulneráveis. Clifford (1982, p. 130) denomina o capítulo 24,1-22 de leis concernentes ao casamento e a proteção dos indefesos. O princípio da fraternidade e da solidariedade norteia o legislador deuteronômico que o leva, sob todas as formas possíveis, a evitar que alguém na sociedade fraterna do povo de Deus viva situações de vulnerabilidade. Provavelmente ele tem como preocupação principal a transformação da realidade socioeconômica. Um objetivo assim descrito por Kramer (2006, p. 89) “tecer a rede mais densa possível de relações fraternais, solidárias, inclusivas e de partilha na sociedade israelita para que ninguém e nenhum grupo social cai numa realidade antifraternal".

A construção da sociedade acontece preferencialmente a partir de medidas de proteção daqueles que vivem à margem e estão, por conta disso, sem possibilidade de proteção externa ou de autoproteção exatamente porque se constituem seja como pessoas ou grupos fracos e/ou enfraquecidos e empobrecidos. Na abordagem de apenas duas situações de proteção dos mais vulneráveis, é necessário refletir sobre o contexto de opressão e exclusão presente na sociedade:

O legislador deuteronômico tem como objetivo acabar com a realidade de classes
sociais e de pessoas excluídas e marginalizadas, empobrecidas e oprimidas, através
de seu Código Legal em Dt 12-28, como explicitação e leis complementares de Dt 5 .
Para alcançar seu objetivo, ele ataca a causa geradora do abismo crescente entre
pessoas e os grupos sociais na sociedade israelita nos séculos VIII e VII a.C. A causa
promotora de exclusão e de marginalização, de empobrecimento e de opressão, é a
concentração de bens e das riquezas nas mãos de poucos, em detrimento das
grandes maiorias, através da comercialização do excedente dos produtos e dos
animais, bem como através dos vários tipos de tributos (KRAMER, 2006,
p. 35).
O objetivo do artigo é o de destacar duas dessas medidas, a saber, a da
nas relações de trabalho (versos 14-15) e a justiça relativa à tríade
(versos 17-18). E, segundo Braulik (apud KRAMER, 2006, p. 170) esses
pequenos blocos literários deveriam ser compreendidos e interpretados 
da seguinte maneira: 24,15 como um julgamento divino por causa do pecado quanto ao pagamento ou não do salário ao diarista ao pôr-do-sol e 24,17 como julgamento humano quanto ao respeito ou não do direito do estrangeiro e do órfão e da roupa da viúva.

\section{A exploração do trabalhador (Dt 24,14-15)}

"14. Não explore um assalariado pobre e necessitado, seja ele um de seus irmãos ou imigrante que vive em sua terra, em sua cidade.

15. Pague-lhe o salário a cada dia, antes que o sol se ponha, porque ele é pobre e sua vida depende disso. Assim, ele não clamará a Javé contra você, e em você não haverá pecado".

Nesses dois versos a categoria social que se apresenta é a dos diaristas assalariados, quer eles fossem israelitas ou mesmo estrangeiros. Kramer (2006, p. 93) afirma que se tratava de trabalhadores que necessitavam vender diariamente sua força de trabalho e, por isso:

Necessitavam também do pagamento diário. Como eles não tinham outros meios de sobrevivência, dependiam totalmente do patrão. A situação socioeconômica deles era extremamente delicada e viviam continuamente ameaçados a serem jogados na mais extrema pobreza.

O verbo "defraudar" está conectado com o furto e a fraude também

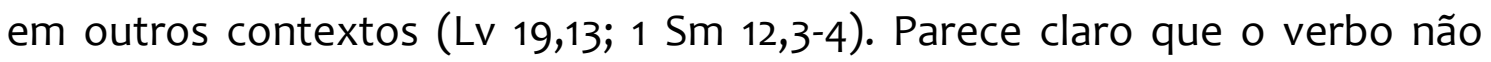
indica diretamente a violência, mas a exploração do outro pela simples sede de lucro e pelo desejo insano de confiscar seus bens. Papola (2011, p. 268) assim descreve o nível de exploração presente no texto:

A vítima da opressão são fundamentalmente caracterizados como próximo por manifestar a traição perpetrada. De modo especial é o pobre (Am 4,1; Pv 14,31; 22,16 ) e às vezes os politicamente fracos (o estrangeiro, o órfão e a viúva). O termo assalariado é pouco atestado na língua hebraica. Assalariado significaria o trabalhador diário, ou seja, aquele que o patrão sai de manhã para contratar e precisa efetuar o pagamento à noite porque o trabalhador precisa desse salário para sobreviver.

É necessário salientar que o trabalhador é descrito a partir de dois adjetivos, isto é, pobre e necessitado. Claro está que o trabalhador não é pobre e necessitado porque é preguiçoso. Percebe-se que a pobreza e a 
necessidade do trabalhador é fruto justamente das relações de trabalho pessimamente estruturadas ou, melhor dizendo, estruturadas a fim de dar vantagem ao empregador. Pobre e necessitado são adjetivos que indicam condição social. Logicamente, não é possível flexibilizar os adjetivos de sua carga social tentando, de uma forma inadequada, suavizar sua carga semântica. Levin (2014, p. 67-68) ratificam que o trabalhador diário é indubitavelmente um pobre. Mas não se trata apenas de um trabalhador diário, o legislador faz questão de enfatizar e defini-lo em aposição assindética como sendo pobre e necessitado. E, a respeito do sentido das relações de trabalho, poderíamos considerar o postulado por Dobberahn (1986, p. 74) ao afirmar que o trabalho tem que servir ao bem-estar coletivo e não pode estar alienado da sua finalidade divina, ou seja, assegurar as necessidades fundamentais, a vida e a liberdade econômica de todo o povo.

Os versos 14 e 15 trazem uma característica que é própria do Deuteronômio ao falar do assalariado israelita ou estrangeiro, haja vista que o Código de Santidade, que possui uma lei semelhante, omite o estrangeiro (LV 19,13). Azcárate (2009, p. 229) nos ajuda a melhor compreender o significado de explorar em semelhante situação:

O verbo utilizado para "explorar" significa "oprimir, expropriar, e implica chantagem através de roubo, fraude ou comportamento tirânico (Lv 19,13; Dt 28,29.33; 1 S 12,4; Jr 21,12; 22,3; Os 4,2; Am 4,1). O termo hebraico para "pobre" na literatura profética é aplicado para aqueles que não tem a segurança das riquezas (Is 14,30; 25,4; Am 8,4 ), aos explorados pelo poderoso (Am 2,6; 8,6), aos oprimidos pelo sistema judicial (Is 32,7; Jr 20,13) e aos maltratados pelos oficiais ou funcionários (Is 32,6-7). O profeta Malaquias, provavelmente sob a influência deuteronomista, inclui o jornaleiro na lista de possíveis oprimidos junto ao órfão, a viúva e o estrangeiro (Ml 3,5). A tradição bíblica, tanto do Novo Testamento quanto do Antigo Testamento, condenará com intensidade a falta de pagamento do trabalhador, que será reclamado por Deus (Jr 22,13-19; Mt 20,8; Mc 10,19; Tg 5,4).

O trabalhador assalariado era especialmente vulnerável porque ele não tinha terra e estava tão somente temporariamente empregado (WOODS, 2011, p.245) e, nesse sentido, seu futuro era completamente incerto. Um trabalhador que vive um dia de cada vez e não se pode dar ao luxo de pensar no amanhã. Nesse sentido, a esperança somente poderia ser germinada na dinâmica de cada dia mediante o pagamento de seu salário. Possivelmente seria possível relacionar o texto com a emblemática situação dos escravos no 
Egito. Kramer (2006, p. 94) reforça essa ideia ao dizer que os versos 14 e 15 reproduziria a situação dos hebreus no Egito:

Quando lahweh tomou o partido dos hebreus e optou por eles contra o faraó, agora representado pelo patrão que oprime o diarista e nega-lhe o salário diário como um direito seu, do qual depende a sua vida. Esse pecado de quebra da fraternidade e da solidariedade tem, aqui uma dimensão teológica e social, pois o patrão rompeu com lahweh e assumiu a atitude do faraó, seu rival e antagônico, ao oprimir o diarista, negando-lhe o salário, que é a sua sobrevivência pura e simples.

O propósito da lei que regula a remuneração a ser paga pelo dia de trabalho é o de prevenir a extorsão e a exploração em linha com o ideal humanitário presente no texto. $O$ ideal humanitário expressa um relacionamento especial existente entre os vulneráveis e Deus. Desses pobres, ou vulneráveis, é dito que eles possuem um relacionamento mais próximo com Deus; afinal, quando ele clama contra aquele que deixou de praticar a justiça, há uma penalidade. Portanto, o compromisso com o pobre se torna um bom trabalho que aparece como crédito no julgamento divino.

Um trabalhador necessitado e carente, quer um israelita irmão ou um estrangeiro residente não deveriam ser oprimidos, ou seja, privados de seus direitos, mas a cada dia seus salários deveriam ser pagos antes do pôr-do-sol (THOMPSON, 2006, p. 236). Sendo pobre, não dispunha de recursos e precisava do dinheiro. Uma vez que seu caso era preocupação de Javé, o não satisfazer suas necessidades resultaria no seu clamor a Javé, que consideraria culpado — "será pecado contra ti" - ( Lv 19:13; Ml 3:5; Tg 5:4). A proteção e defesa dos grupos mais vulneráveis é forte em toda esta seção $(6,7,10-13,17,18,19-22)$. Pode-se perceber que para o legislador deuteronômico era fundamental que todo o Israel compreendesse perfeitamente bem que o Deus que libertara Israel do Egito tinha uma forte preocupação pelos fracos e menos favorecidos.

Clifford (1982, p. 131) insiste que o conteúdo desses versos continua a enfatizar a justiça social e acrescenta: "pessoas pobres não podem esperar pelo pagamento de seu salário de acordo com a conveniência de seu patrão" e Blenkinsopp (2007, p. 244) sublinha a necessidade de se pensar a justiça social a partir da cotidianidade: "o dia de trabalho deve ser pago diariamente". O recurso financeiro sempre será mais curto do que o dia de trabalho e, por conta disso, a necessidade de pagar o dia trabalhado. Poderíamos ainda lembrar de dois textos que registram a mesma preocupação relativa ao salário, a saber, Levítico 19,13 - "o salário do jornaleiro não ficará contigo até pela manhã" — e Tiago 5,4 — “Eis que o 
salário dos trabalhadores que ceifaram os vossos campos e que por vós foi retido com fraude está clamando; e os clamores dos ceifeiros penetraram até aos ouvidos do Senhor dos Exércitos". Assim como o manto do pobre deve ser devolvido no por do sol, o assalariado deve receber seu pagamento no por do sol. A situação em que ele vive pode ser considerada uma situação limite, ou seja, ele não pode suportar qualquer tipo de atraso! Afinal, como os assalariados eram sem-terra, possuíam empregos temporários e não eram membros das famílias contratantes, estavam certamente expostos à expropriação.

O trabalhador pobre é visto a partir de seu relacionamento próximo com Deus e, por isso, seria mesmo possível acrescentar que a relação de uma pessoa com Deus é decidida pelo seu comportamento relativamente ao pobre. Em nosso texto encontramos uma variante negativa, ou seja, a falta de compromisso e de solidariedade para com o pobre e, mais do que isso, o não pagamento do salário do trabalhador, configurando para ele - o trabalhador - como um risco de morte. Consequentemente, a deliberada recusa em se comprometer com o pobre trabalhador e colocá-lo em risco iminente de vida, é reputado como pecado no julgamento divino. A benção ou a maldição estão condicionadas, de certa forma, à maneira como nos relacionamos com os pobres. Em caso de não observância da lei socioeconômica, ela provocaria de imediato o clamor do diarista. Aqui reside um dado teológico de grande importância, pois até o momento se tratava de relações do mundo do trabalho e, ao concluir a lógica dos versos 14-15, somos surpreendidos por uma lógica teológica que define o critério das relações civis a partir da proteção do diarista pobre e necessitado!

Notadamente, percebe-se que o trabalhador pobre e necessitado possui uma única fonte de segurança e de proteção e ela é Javé. Numa sociedade em que a rede de proteção que permitia relativa segurança aos mais vulneráveis já não dava mais sinais de existência, Javé se apresenta como o guardião dos trabalhadores expropriados de seu salário.

A conclusão de ordem teológica nessa relação civil do cotidiano é possivelmente a de que o pecado no Deuteronômio seria a simples recusa de viver a fraternidade e a solidariedade. A linguagem utilizada nos versos 14 e 15 faz claramente um apelo ao tema da fraternidade e, sem dúvida, sinaliza que o cálculo econômico deve ser subordinado à compaixão. Todo aquele que retém do trabalhador os meios necessários e essenciais para a sua sobrevivência, produz uma relação de inadequação com Javé pois, de forma muito concreta, ele produz contra si mesmo provas incontestáveis de que está em pecado, isto é, o empregador agiu 
de forma violenta contra aquele que é protegido por Deus. Se o patrão não usar de compaixão poderá, certamente, evitar o tribunal terreno, mas continuará em erro com lahweh. Para o trabalhador pobre e necessitado o tribunal de apelação é o próprio lahweh.

\section{A tríade social (Dt 24,17-18)}

"17. Não distorça o direito do estrangeiro e do órfão, nem tome como penhor a roupa da viúva.

18. Lembre-se: você foi escravo no Egito e daí Javé seu Deus o resgatou. É por isso que eu lhe ordeno agir desse modo".

Buis \& Leclerc (1963, p. 163) recordam que a defesa dos mais vulneráveis é um tema clássico do mundo antigo e que figura regularmente ao retratar os heróis e reis legendários. Os versos 17 e 18 protegem os direitos daqueles que não possuem parentes próximos que os protejam e, por isso, são mais suscetíveis de ser facilmente explorados, isto é, o estrangeiro (refere-se ao estrangeiro residente), o órfão e a viúva. No Deuteronômio encontramos vários textos que referenciam de forma explícita o conjunto social formado pelo estrangeiro, pelo órfão e pela viúva, a saber, 10,12-22; 14,28-29; 24,17-21; 26,12-15; 27,11-26). No entanto, por trás da lei de proteção há como uma motivação histórico-teológica, ideia reforçada por Azcárate (2009, p. 230):

A frase com motivação para proteger o direito destas pessoas é claramente deuteronômica (Dt 7,8; 9,26; 13,6; 15,15; 21,8), ainda que esteja também presente no Código da Aliança (Ex 22,20-23; 26,12-13) e no Código de Santidade (Lv 19,34.36; 25,38.42.55): a recordação de que Israel foi escravo no Egito e resgatado por lahweh. No verso 18 aparece outra vez o verbo "resgatar" ou "libertar" associado à libertação do Egito, algo próprio, como já expressado, no Deuteronômio (Dt 7,8; 9,26; 15,15; 21,8).

O verbo "perverter" ou "distorcer" no início do verso 17, de acordo com Papola (2011, p. 270) é usado com certa frequência no âmbito do léxico forense com o objetivo de exprimir a perversão da justiça ou do direito. E sublinha ao afirmar que nesse verso é indicado para quem é injustiçado. "Distorcer o direito" significaria agir de modo desonesto, como é facilmente o caso do preconceito contra o estrangeiro ou da influência econômica contra o órfão e a viúva.

Os sujeitos que sofrem a ação violenta e desumana são o estrangeiro, o órfão e a viúva. Mais do que representantes de situações individuais, 
possivelmente representam o coletivo de todos aqueles (as) que vivem em igual condição de miserabilidade. Segundo Frizzo (2011, p. 21):

\begin{abstract}
Fala-se desses grupos sociais em um sentido sempre restrito, definido e inserido em uma determinada situação de demanda, de pessoas que se veem envolvidas numa esfera de violação de seus direitos e, ao mesmo tempo, têm a consciência de que, sem a proteção legal, se encontram à mercê da própria sorte, isto é, correm o risco de morte. Ao referir-se aos grupos socialmente empobrecidos - constituídos por camponeses, trabalhadores em obras públicas e famílias de estrangeiros - nota-se que tais grupos experimentam um rápido processo de empobrecimento.
\end{abstract}

Da viúva se diz que é proibido tomar sua veste. Provavelmente a veste da viúva seja uma alusão a uma vestimenta que a caracterizaria como sinal distintivo de sua condição, ou seja, ela própria com a sua vestimenta, por onde quer que andasse, seria rapidamente reconhecida e, por consequência, estigmatizada. Trata-se, portanto, de uma mulher que levava para todos os lados e caminhos que fazia não um nome ou uma identidade e, sim, um estigma que a tornava diferente, inferior e destinada à periferia da vida, em detrimento de todos os outros.

Clifford (1982, p. 131) e Thompson (2006, p. 238) nos recordam que a tríade social são não somente estereótipos retóricos do Antigo Testamento, mas, também, na literatura do Egito e de Canaã. São grupos que não possuem quem os defenda. Até mesmo o rei que deveria defendê-los, por força de sua função, deixa de cumprir uma de suas mais distintas obrigações. Os reis do antigo oriente próximo ostentavam que eles cuidavam daqueles negligenciados pela sociedade com paternal cuidado (CLIFFORD, 1982, p. 131; BUIS \& LECLERC, 1963, p.164, WOODS, 2011, p. 253). No entanto, na tradição do povo de Deus há uma preciosa particularidade, ou seja, não somente o rei (SI 72,11-14; Jr 15,16) seria considerado o responsável direto pelos grupos vulneráveis e, sim, toda a sociedade israelita assumiria a mesma responsabilidade - com cuidado paternal - por causa da "memória teológica" de que haviam sido escravos no Egito e, por isso, cada um deveria indistintamente socorrer qualquer pessoa indefesa (Ex 22,20; 23,6-9; Lv 19,33; Dt 10,18; 27,19; Pv 22,22; Ez 22,7).

Essa também é a clara compreensão de Chouraqui (1997, p. 249) “Javé tem o direito de pedir a seu povo que seja justo e clemente com os 
deserdados porque ele o resgatou da escravidão do Egito. Israel lhe pertence e deve, portanto, obedecer a suas ordens". Possivelmente estamos diante de uma responsabilidade comunitária que produz uma espiritualidade não somente comunitária, mas, também, solidária e inclusiva. Woods (p. 254) reforça a mesma compreensão, ao afirmar que a motivação para o comportamento de se solidarizar com os grupos mais vulneráveis é justamente a recordação de que eles haviam sido escravos no Egito. Dessa forma, a lembrança da experiência de escravidão no Egito deveria despertar empatia em cada um daqueles que pertenciam ao povo. É interessante a percepção de Papola (2011, p. 271) ao afirmar que a expressão que consta em Dt 24,18 - "lahweh [...] o resgatou" - "é um tipo de Credo em miniatura que tem clara implicação com a justiça social (Dt 7,8; 9,26; 13,6; 15,15; 21,8)".

A razão apresentada para tal preocupação com os fracos e indefesos é que Israel fora um escravo indefeso no Egito, e Javé o libertara (padah). A ênfase particular na libertação de lahweh (padah) pode ser considerada em si mesma uma poderosa declaração teológica com significativas implicações de justiça social. Papola (2011, p. 271) reafirma que na conclusão da norma, a articulação do discurso passa da proteção do estrangeiro para a memoria da própria escravidão no Egito e da libertação, apresentada no termo legal do resgate. E, segundo Kramer (2006, p. 173), o verbo padah é usado para descrever a libertação dos escravos no Egito e, portanto, a relação com o texto de Deuteronômio pareceria muito próximo:

Expressa-se que lahweh "resgatou", isto é, pagou com dinheiro o "resgate" deles, tornando-se, assim, legalmente proprietário do povo de Israel e este, "propriedade" de Deus lahweh. Como lahweh, portanto, resgatou Israel do poder do faraó, tornando-se seu proprietário, assim também agora os israelitas, que cultivam a terra de Canaã, partilham de suas colheitas com os necessitados para que não haja empobrecidos e excluídos na sociedade israelita.

\section{Conclusão}

As instruções sociais analisadas apelam para a defesa do direito dos pobres, daqueles que são fracos e endividados e, por isso, visam erradicar, de uma vez por todas, a existência de empobrecidos e de excluídos da sociedade israelita.

Se estamos ao redor de uma sociedade eminentemente agrícola, seria razoável concluir que todos os membros da comunidade da aliança têm o 
direito adquirido de desfrutar da benção da terra e viver na terra que é, em última instância, dom de Deus para o povo.

Os dois textos bíblicos selecionados levam o leitor a refletir a respeito da construção de uma sociedade a partir da proteção dos mais vulneráveis. Aqueles que vivem sem proteção precisam, de forma urgente, que se crie uma rede de proteção ao redor deles. A falta de proteção expunha os grupos mais vulneráveis à violenta exploração por parte de grupos sociais mais fortes. Assim, os textos apelam para a sensibilidade da comunidade israelita de forma geral e para os sujeitos de poder, de forma particular, para que os grupos sociais vulneráveis tenham vida e vida em abundância.

\section{Referências}

AZCÁRATE, J. L. L. Deuteronomio. Henao: Desclée de Brouwe, 2009.

BLENKINSOPP, J. Deuteronômio. In: Novo comentário bíblico São Jerônimo - Antigo Testamento. São Paulo: Paulus, 2007.

BUIS, P. \& LECLERC, J. Le Deutéronome. Paris: J. Gabalda, 1963.

CHOURAQUI, A. A Bíblia. Palavras (Deuteronômio). Rio de Janeiro: Imago, 1997.

CLIFFORD, R. Deuteronomy. Delaware: Michael Glazier, Inc, 1982.

DOBBERAHN, F. E. "Trabalho e direito fundiário. Observações a partir do Antigo Oriente. Revista estudos Bíblicos 11, Petrópolis, p. 69-75, 1986.

FRIZZO, A. C. "Uma tríade social que qualifica o ato de conhecer a Deus". Revista Pistis \& Práxis, v. 3, n. 1, jan./jun. p. 15-42, 2011.

KRAMER, P. Origem e legislação do Deuteronômio. Programa de uma sociedade sem empobrecidos e excluídos. São Paulo: Paulinas, 2006.

LEVIN, C. "Rereading Deuteronomy in the Persian and Hellenistic Periods: The Ethics of Brotherhood and the Care of the Poor". In: Deuteronomy-Kings As Emerging Authoritative Books. Atlanta: SBL, 2014.

PAPOLA, G. Deuteronomio. Introduzione, traduzione e comento. Roma: San Paolo, 2011. 
THOMPSON, J. A. Deuteronômio. Introdução e comentário. São Paulo: Vida Nova, 2006.

WOODS, E. J. Deuteronomy. An Introduction and Commentary. Downers Grove: IVP, 2011.

RECEBIDO: $19 / 04 / 2019$

RECEIVED: 04/19/2019

APROVADO: $27 / 06 / 2019$

APPROVED: 06/27/2018 